\title{
Interpretation on Chinese Linguistics from the Language Skills of $A$ Dream in Red Mansions
}

\author{
Yueping Wang \\ Zhengzhou University of Science and Technology, Zhengzhou Henan, 450001, China
}

Keywords: Chinese linguistics, A Dream in Red Mansions, Language skills

\begin{abstract}
Among Chinese classical novels, A Dream in Red Mansions is a great model full of language arts among numerous literary works. Because of different personal characters, their language expressions are also different, both Wang Xifeng' s interaction languages and Lin Daiyu' s frank and critical language expressions can reflect their personal characters. Through language performance, the story line including the inner world and psychological features of figures can be judged, we can achieve enlightenment from interpretation on A Dream in Red Mansions. In Chinese language and literature, language expression will change with the change of context to make the language connotation different for different usage. This paper is an interpretation on the language skills of A Dream in Red Mansions.
\end{abstract}

\section{Introduction}

At the end of the $20^{\text {th }}$ century, there were lots of research achievements on A Dream in Red Mansions, among which, language expression was an important research subject. A Dream in Red Mansions presented the Chinese Language culture during its period of creation, including oral expression, written language expression and so on, which not only located the personal characters and psychological states of the figures, but also made a foreshadowing for the follow-up development of the story. Language permeation in the whole novel makes the fragmented story line full of abundant language expression, thus the novel becomes more attractive.

\section{Languages in A Dream in Red Mansions reflects the language view of Cao Xueqin}

Language of A Dream in Red Mansions is highly personalized, for its distinctive language style, some researchers called the Language of A Dream in Red Mansions as language "blood" that can connect the whole novel, figures' $\mathrm{s}$ view of life, philosophy can be located through language expression and expression content. The function of language of A Dream in Red Mansions is to connect the story line and make foreshadowing, which expresses that language usage and expression in the novel has some skills. Language is not only culture, but also art. Language can be ornament, language can also be deleted and revised, skillful use language in the novel to render story line should start from the story content to choose, process and synoptically express languages. Cao Xueqin used language style of traditional novels, exerted language features of literariness and nationality in A Dream in Red Mansions. Besides, languages usage in A Dream in Red Mansions, including choice of words, structure of statement and the purpose of language should be studied in-depth, thus can get a better understanding of Cao Xueqin. One of the features of Language of A Dream in Red Mansions its implication. It leaves readers imagination space, materialize the abstract languages, and makes readers gradually extend their thoughts. Same words on different figures implicates their inner connects, maybe destiny, maybe characters or interests, by skillfully using languages, Cao Xueqin makes all kinds of information of different figures can be understood.

\section{Interpretation on the language skills of Wang Xifeng}

In A Dream in Red Mansions, Wang Xifeng has special position and status, which can be seen from her language features with Grandmother Jia. The location of Wang Xifeng' s language style is "hear one's voice before seeing the person", which has a momentum in all occasions of Jia mansion. 
The $3^{\text {rd }}$ chapter of A Dream in Red Mansions, "Jia Yucun resumed to his position by making use of relationship of Lin Ruhai, Lin Daiyu left her father for Jinling"

At the first meet, Wang Xifeng' s words can makes the smart Lin Daiyu judge her identity and status in Jia mansion. In the language expression of Lin Daiyu's meet with Grandmother Jia, though there are lots of people, while every one is silent, at this time, Wang Xifeng appears, speaks with laugh and reveals some dissipated and unreasonable, "Oh I am late, I've missed the arrival of our guest!" her laughter and word suddenly defuses the serious atmosphere. Such behave in front of Grandmother Jia has already explained Wang Xifeng's important status in Grandmother Jia.

When Wang Xifeng saw Lin daiyu, she makes an evaluation on Lin Daiyu, while her words cater to Grandmother Jia's psychology. "If I hadn't set eyes on her today, I shouldn't have believed that such a beautiful creature could exist! ... She doesn't take after your side of the family, Grannie. She's more like a Jia. ... What a cruel fate to have lost Auntie like that!" The first sentence is the praise for Lin Daiyu, then flatters Grandmother Jia, then finish her words by conveying her own emotions. Wang Xifeng expresses her thoughts through language, in her evaluation on Lin Daiyu and her conversation with Grandmother Jia, she expressed her inmost thoughts and behaviors. All these contents have a foreshadowing for the later description of her. Then Wang Xifeng uses languages of order to servants "You'd better hurry up and get a couple of rooms swept out for them to rest in.". Her management position and authority in Jia mansion is expressed out. Besides, she told Lin Daiyu "If you want something to eat, something to play, just tell me", this expressed care from the elders, also told Lin Daiyu that she is charge of such kind of things in Jia mansion.

In the whole expression, Wang Xifeng's words are very simple but with abundant information, at the same time with praising Lin Daiyu, she flattered Grandmother Jia, and also praised the attendant Yingchun, Tanchun and Xichun. From her high-sounding appearance to sad tears, Wang Xifeng's performance is very flexible. For all the readers, this classic paragraph has strong infection.

The $46^{\text {th }}$ chapter of A Dream in Red Mansions "Embarrassed people cannot avoid from embarrassing things, Yuanyang refused her marriage with Jia She"

In this chapter, Jia She asked Lady Wang to help him to marry Yuanyang as concubine. According to her knowing for Yuanyang and Grandmother Jia, Wang Xifeng knows that Lady Wang will be refused absolutely, thus she asks Lady Xing to advise Jia She give up this thought. While Lady Xing is stubborn and doesn't listen to the advise and becomes angry, thus Wang Xifang said the following languages:

"You are pretty right." Wang Xifeng affirmed Lady Xing's words, then blamed herself as too young to understand, and helped Lady Xing to find ways "I go to make Grandmother happy first...then you can discuss with grandmother." Of course, these words came after Lady Xing's against attitude, then make a remedy by saying these words. Though Wang Xifeng made Lady Xing feel unhappy, Wang Xifeng changed her attitude and stand very quickly. Thus we can see Wang Xifeng's sense motive, and she can make every one feel happy within a very short time.

In logistics, the purpose of language is to maintain social relationships through interaction among people.Though there are all family matters description in A Dream in Red Mansions, especially the descriptions in the Grand View Garden. While the big family like Jia mansion is a social group already. The story of Jia mansion that described by Cao Xueqin, actually is a description of social interpersonal communication at that time.In A Dream in Red Mansions, the function of language is not just limited in the simple family communication, but to convey all kinds of information of the speakers, including their identity, status in the group, their opinions, and purpose of their words.Relationships of speakers also can be judged through the context.Few words of Wang Xifeng when she first appeared have already reflected her identity, status in Jia mansion and her character.Communicate freely with Grandmother Jia--the one with highest position in Jia mansion, we can see Wang Xifeng's status in Jia mansion is no one can compare.Lin Daiyu realized that.Every one was so serous, while Wang Xifeng's appearance broke this atmosphere. When Lin Daiyu stood up to greet Wang Xifeng, Grandmother Jia said with laughter "You do not know her,she's a holy terror this one. What we used to call in Nanking a "peppercorn". You just call her "Peppercorn Feng". She'll know who you mean! "She can be teased by Grandmother Jia, thus can say Wang Xifeng is 
loved by Grandmother jia.For the establishment of social identity, Eggins thought that the special identity of a person is not confirmed by the figure but through language communications. Therefore, besides figure, social identity is expressed from conversations, attitude and expression performance in the communication.Wang Xifeng' s identity and status in Jia mansion and her character features is obvious to readers through her languages during the first appearance ${ }^{[1]}$

Wang Xifeng's language expression is full of strong skills, as the steward of Jia mansion, communicate with the big family, her language skill is astonishing.If we say, she expressed her understanding of the worldly wisdom at the first meet with Lin Daiyu, then, her communication with her mother-in-law about Jia She' plan on marrying Yuanyang as concubine showed her sleek sophistication. When Lady Xing asked Wang Xifeng to say kind words to Grandmother Jia, Wang Xifeng knew it was not applicable, when she found it was not applicable, she changed topic at once and changed her attitude accordingly.Wang Xifeng's admonish will arouse Lady Xing's suspect.In order to make Lady Xing give up this suspect, Wang Xifeng said "Pretty right" to confirmed her thought.Then blamed herself "How old am I ? I can I know what important things are?"she implicates that she is too yound to understand, ask for her mother-in-law's forgiving.After listen to her words, Lady Xing's anger became mild.Then she showed her support to Lady Xing "Such a beautiful girl, if not give to master, who will give to?"she made Lady Xing believe her opinion that Grandmother will marry Yuanyang to Jia She.Thus she canceled Lady Xing' s suspect, also made a foreshadowing for Lady Xing's behavior.Lady Xing plans to ask Wang Xifeng to say good words to Grandmother Jiia, Wang Xifeng's words let Lady Xing know she was too young to understand things, and encouraged Lady Xing to propose this thing to Grandmother Jia by herself, then she can escape from it.

We can see that Wang Xifeng is good at observing others' every mood in the interpersonal communications. Flattering in front of Grandmother Jia, being a elder in front of younger ones, making orders to servants and escaping from troubles.

\section{Interpretation on Lin Daiyu's language skills}

For the shape of Lin Daiyu in the novel, the writer Cao Xueqin paid lots of energies. Lu Xun evaluated the language skill of A Dream in Red Mansions, he thought figures in the novel were described according to the fact, not like other novels that good man is pure good, bad man is pure bad, thus figures in the novel are real figures. Shape of Lin Daiyu is exactly like this.

Readers can feel Lin Daiyu' s oversensitive and nitpick, but this also is her frank character. This character can be expressed from her words.

The $31^{\text {th }}$ chapter of A Dream in Red Mansions "Qin Wen tore fan with Jia Baoyu for fun, the servant found the gold kili and talked about marriage"

(Lin Daiyu) talks with Xi Ren with laughter: "You said you are a servant, while I treat you as my sister-in-law."The relationship between Jia Baoyu and Xi Ren is ambiguous, that is known to all in the Grand View Garden. Even Qing Wen will not talk it directly, while Lin Daiyu reveals the relationship directly. Though there is irony and insulting in her language, it is the truth.

The $48^{\text {th }}$ chapter of A Dream in Red Mansions, "Xue Pan wants to play outside, Xiangling learns to write poems"

Xiangling wants to learn to write poems, and asked Lin Daiyu to teach her. Daiyu said: "Though I am not good at writing poem, I can teach you."there we can see, Lin Daiyu did not praise herself for writing poem, while she said modestly "Though I am not good at writing poem"which made Xiangling feel comfortable. This kind of expression can also express that Lin Daiyu treats Xiangling in the same way as other girls in the Grand View Garden. Thus we can tell Lin Daiyu is modest and gentle, she will not treat other people according to their identities.

The $3^{\text {th }}$ chapter of A Dream in Red Mansions "Lin Ru-hai recommends a private tutor to his brother-in-law And Grandmother Jia extends a compassionate welcome to the motherless child."

After arriving at Jia mansion, when visited Lady Xing, Lady Xing asked her to have dinner. Lin Daiyu replied with smile: "Aunt asked me to have dinner, I should not refuse,...but I should also visit Uncle Zheng, I fear that it might be disrespectful if I arrived late....I hope Aunt can forgive me." In the feudal family, the younger should show their respect to the elder when speak with them. Daiyu' $\mathrm{s}$ 
reply comply with feudal ethical code. From her words, we also can tell that Daiyu has received good family education. Though Lin Daiyu' s word are very acrid, born in a declining noble family, influenced by her family, she is very gentle in the interpersonal communication.

A Dream in Red Mansions is developed with the love story between Jia Baoyu and Lin Daiyu. Lin Daiyu convey thoughts and emotions through languages, while for the influence of feudal ethical code, she will not express directly, thus she will use the specious manner or the language of resistance to express her love ${ }^{[2]}$.

The $29^{\text {th }}$ chapter of A Dream in Red Mansions "Favorites of fortune pray for better fortune, An absurd, loving girl falls deeper in love"

Jia baoyu did not go to the opera for the Taoist Zhang's marriage propose, Lin Daiyyu did not understand, thus they had a quarrel. Jia Baoyu angered for Lin Daiyu's misunderstanding, said: "My friendship with you has been of no avail! Never mind!" Lin Daiyu said: "You are afraid of me to break your good marriage,...you anger at me." Here Lin Daiyu used "good marriage" to compel Jia Baoyu, while it caused upgrade of their contraction for misunderstanding. Lin Daiyu's special expression way also was well-designed by Cao Xueqin, to embody Lin Daiyu's insistence for love.

\section{Conclusion}

In conclusion, Eggins \& Slade thought that the meaning of conversation is to exchange, as a member of social groups, language should be his expressive activity, to achieve the expected targets for the drive of its function. Thus the conversation should be with structure strict, it is a composition of mood, emotion, psychology and evaluation. Jia mansion created by Cao Xueqin, actually is a side reflection of the social society at that time. In the feudal family like Jia mansion, the language is not expressed freely but with sociality. The connotation of language should be investigated by combining the speaker's identity, interpersonal relationship, character and so on, thus can truly understand the purpose of language.

\section{References}

[1] Chen Yun,Li Jie. Analysis on the Interpersonal Significance Structure of Wang Xifeng's Language. Journal of Hu Nan Industrial Vocational and Technical College, 2013,13(02):70-71.

[2] Zheng Sheng, Li Jie. Discussion on the Love Language Art of A Dream in Red Mansions. Modern Chinese, 2013(01):25-27. 